\title{
Novel rapid measurement system of undisturbed soils water characteristics curve utilizing the continuous pressurization method
}

\author{
Adel Alowaisy ${ }^{1, *}$, Noriyuki Yasufuku ${ }^{1}$, Ryohei Ishikura ${ }^{1}$, Masanori Hatakeyama ${ }^{2}$, and Shuu Kyono ${ }^{2}$ \\ ${ }^{1}$ Kyushu University, Department of Civil and Structural Engineering, Fukuoka 819-0395, Japan \\ ${ }^{2}$ OYO Co., Ltd., Niigata 950-0864, Japan
}

\begin{abstract}
Through this paper, a sampling methodology and a novel full automatic system adopting the continuous pressurization method which is capable of determining the Soil Water Characteristics Curve (SWCC) for both remoulded and undisturbed samples in a very short time were developed. The proposed system was validated by comparing the SWCCs of standard testing soils obtained using the developed system to the SWCCs obtained using a conventional method. Remoulded and undisturbed natural soil samples were tested, where the degree of disturbance influence on the obtained SWCC was discussed. In addition, the undisturbed samples containing moulds material influence on the obtained SWCC was investigated. It was found that remoulded samples do not properly represent the in-situ conditions with significant error that should be carefully considered when conducting analysis and proposing countermeasures against unsaturated soils related Geo-disasters. In addition, the material which the containing mould is made from has minor influence on the obtained SWCC which can be neglected. Finally, it can be concluded that the developed undisturbed soil water characteristics curve obtaining system is direct, rapid, reliable and simple. In addition, the proposed undisturbed sampling and testing methodology can be used to accurately evaluate the spatial variations of the SWCC regardless the heterogeneity of the soil profile.
\end{abstract}

\section{Introduction}

Recently earthquakes, typhoons and heavy rainfalls induced natural Geo-disasters occur at different locations causing serious damage to life and properties. Through heavy rain periods, the water table and river water level rise causing increase in the pore water pressure resulting in total strength and stability loss through soil embankments which finally leads to failure.

The proper determination of the hydrological and water retention properties of porous mediums is necessary for understanding the unsaturated soils behaviour. Among those properties, the Soil Water Characteristic Curve (SWCC) is a key index used for estimating many unsaturated soil relations such as the hydraulic conductivity function, water storage, shear strength and prediction of solute and contaminant transport $[1,2]$.

The SWCC is a function that describes the amount of water (volumetric water content, water content or degree of saturation) retained in a soil at a given range of suction values (the difference between pore air pressure and pore water pressure).

Several experimental setups and numerical methods for obtaining the SWCC were developed such as the hanging column, Tempe cells, pressure plate, tensiometers, psychrometer, chilled mirror hygrometer,

\footnotetext{
* Corresponding author: adel owaisi@yahoo.com
}

filter paper, centrifuge and humidity chamber [3-8]. Detailed reviews illustrating the advantages and disadvantages of the existing methods can be found in literature [7-9]. In general, the existing laboratory techniques are limited due to the testing complexity, applicable only under the drying phase, discrete suction and water content measurements and prolonged testing time where depending on the amount of data points desired, testing may require at least several weeks or even

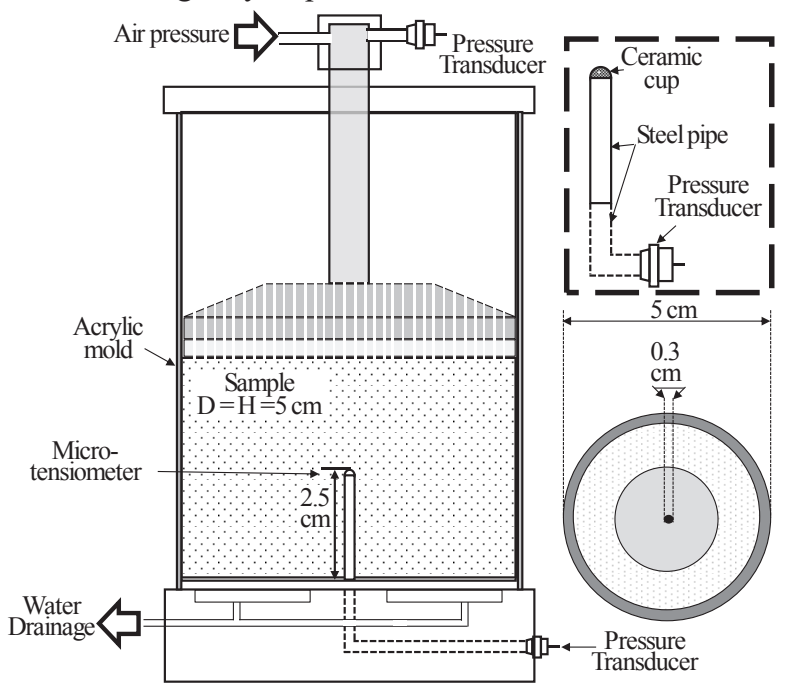

Fig. 1. CPM system, pressurizing cell (schematic). 
several months. In addition, those setups consider testing remoulded samples where little attention has been given for obtaining undisturbed samples SWCC.

Through this paper, a sampling methodology and a novel full automatic system adopting the Continuous Pressurization Method (CPM) that allows for continuous, direct accurate determination of the SWCC in a very short time considering both remoulded and undisturbed samples is proposed. The proposed system is then validated by comparing the obtained results to the results obtained using the conventional axis-translation technique (Tempe cells).

\section{Methodology and materials}

\subsection{Testing setup}

The newly developed CPM based testing system is fully automatic and allows for continuous measuring of the air pressure, pore water pressure and amount of drained water. A schematic diagram of the CPM cell is shown in Fig. 1. During testing, the air pressure is supplied through the air inlet valve attached to the top of the cell, where a regulator connected to a computer controls the air pressurizing rate. Meanwhile, a micro-tensiometer installed at the centre of the sample instantly measures the developing pore water pressure in response to the changing air pressure. The ceramic disk at the bottom retains the air pressure and allows water to drain through the drainage outlet. The water drains into a container that is continuously weighed using a balance with $0.001 \mathrm{~g}$ readability that is directly connected to the data acquisition system.

The matric suction $(\Psi)$ can be calculated by taking the difference between the air pressure $\left(\mathrm{u}_{\mathrm{a}}\right)$ applied to the top of the specimen and the developing pore water pressure $\left(u_{w}\right)$ measured using the micro-tensiometer installed at the centre of the sample $\left[\Psi=\mathrm{u}_{\mathrm{a}}-\mathrm{u}_{\mathrm{w}}\right]$. While the water content can be deduced from the drained water in relation to the initial or final water content of the sample.

A pressurizing rate of $0.05 \mathrm{kPa} / \mathrm{min}$. was adopted for all tested specimens. It was reported that the air pressurizing rate has minor influence on the SWCC determination utilizing the CPM that can be neglected. In addition, it was shown that water get lost non-uniformly and from localized regions depending on the pressurizing rate and the tortuosity of the tested soil. However, the centre of the sample can be considered as a representative pore water pressure measuring point which results in obtaining reliable SWCCs that are in well agreement with the SWCCs obtained using the conventional methods $[10$, $11,12]$. More details are provided in appendix I.

\subsection{Materials and sampling locations}

Tests were conducted using three standard testing sandy soils and natural samples collected at three Geo-disaster affected sites. After Kumamoto earthquake, Japan in April 2016, massive landslides as a result of the jolts and the following rainfall events have occurred. Samples were collected in the middle of October the same year next to a
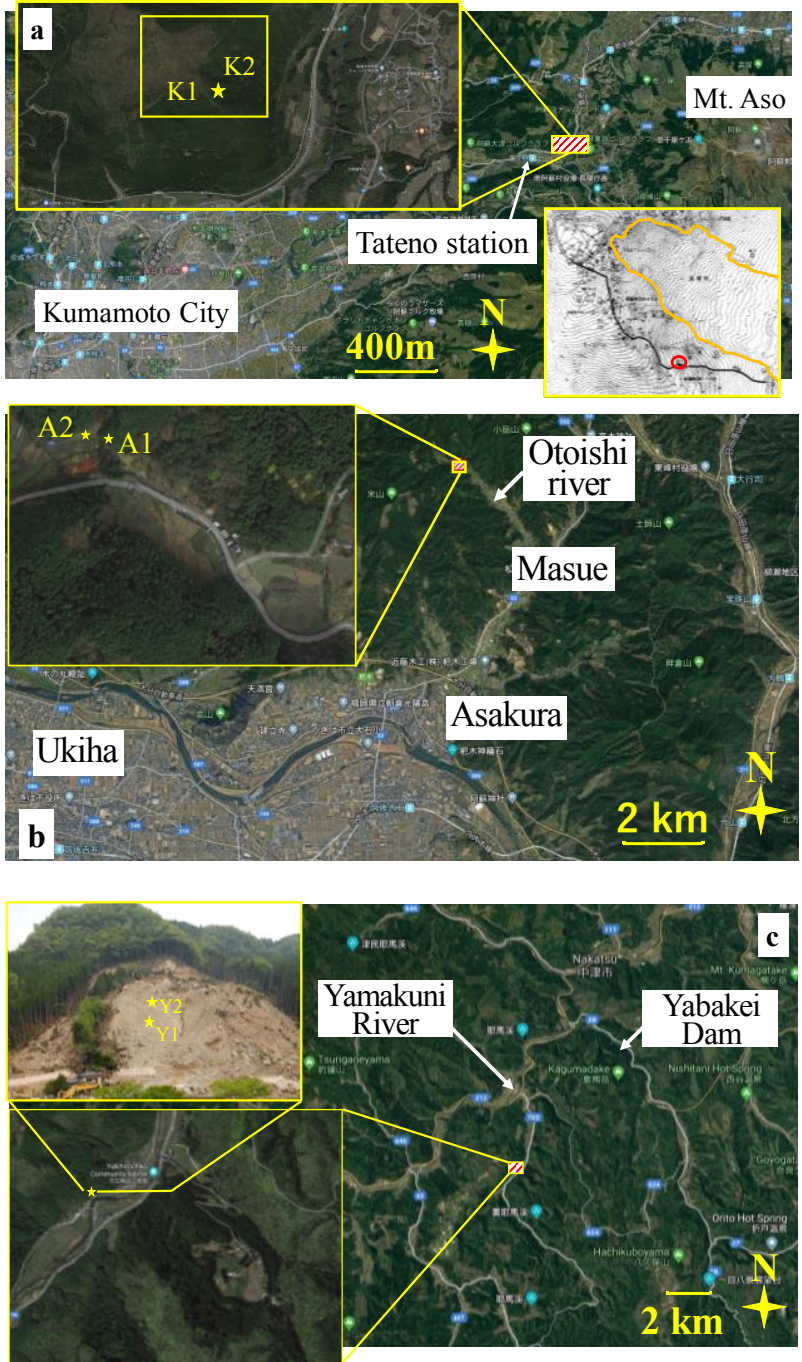

Fig. 2. Natural soil sampling locations. Three landslides were selected. a) April 2016 earthquake, Kumamoto prefecture, Japan. b) July 2017, Asakura region, southern Fukuoka prefecture, Japan. c) April 2018, Yabakei valley, Oita prefecture, Japan.

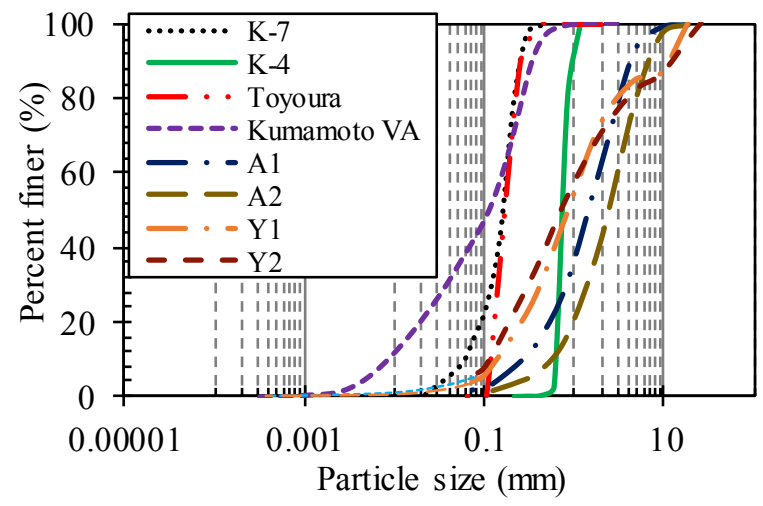

Fig. 3. Standard and natural soils particle sized distribution curves.

huge landslide. Fig. 2 illustrates the sampling location. Several massive heavy rainfalls induced landslides occurred in Fukuoka and Oita prefectures, Japan in the beginning of July 2017. One of the highly affected areas was Asakura region located in southern Fukuoka, Japan. 
Samples were collected in the middle of November the same year at the landslide boundary as indicated in Fig. 2 b. In addition, samples were collected at a landslide that has occurred at Yabakei valley, Oita prefecture, Japan in April 2018 as illustrated in Fig. 2 c. Undisturbed and disturbed samples were collected at the landslide sampling locations indicated through Fig. 2. The particle size distribution curves, summary of soil properties and natural soil characteristics for both standard and natural soils are shown in Fig. 3, Table 1 and Table 2 respectively.

Table 1. Standard and natural soils properties.

\begin{tabular}{|c|c|c|c|c|c|c|}
\hline \multicolumn{2}{|c|}{ Soil } & $\begin{array}{l}\text { Specific } \\
\text { gravity }\end{array}$ & $\begin{array}{c}\text { Dry } \\
\text { density } \\
\left(\mathrm{g} / \mathrm{cm}^{3}\right)\end{array}$ & $\begin{array}{c}\mathrm{k}_{\mathrm{s}} \\
(\mathrm{m} / \mathrm{s})\end{array}$ & $\begin{array}{c}\text { Void } \\
\text { ratio } \\
\mathrm{e}\end{array}$ & $\begin{array}{r}\mathrm{D}_{10} \\
(\mathrm{~mm})\end{array}$ \\
\hline \multicolumn{2}{|c|}{$\mathrm{K}-7$} & 2.642 & 1.618 & $1.14 \times 10^{-5}$ & 0.629 & 0.059 \\
\hline \multicolumn{2}{|c|}{$\mathrm{K}-4$} & 2.640 & 1.551 & $2.07 \times 10^{-3}$ & 0.698 & 0.630 \\
\hline \multicolumn{2}{|c|}{ Toyoura } & 2.646 & 1.560 & $1.29 \mathrm{x} 0^{4}$ & 0.693 & 0.116 \\
\hline \multicolumn{2}{|c|}{$\begin{array}{c}\text { Kumamoto } \\
\text { VA }\end{array}$} & 2.278 & 0.420 & $8.04 \times 10^{-8}$ & 4.440 & 0.008 \\
\hline \multirow{2}{*}{ Yabakei } & $\mathrm{Y} 1$ & 2.619 & 1.199 & $1.131 \times 10^{-3}$ & 0.991 & 0.140 \\
\hline & $\mathrm{Y} 2$ & 2.654 & 1.317 & $8.444 \times 10^{4}$ & 1.219 & 0.120 \\
\hline \multirow{2}{*}{ Asakura } & $\mathrm{A} 1$ & 2.701 & 1.425 & $1.08 \times 10^{-3}$ & 0.850 & 0.285 \\
\hline & $\mathrm{A} 2$ & 2.711 & 1.611 & $2.15 \times 10^{-3}$ & 0.658 & 0.590 \\
\hline
\end{tabular}

Table 2. Natural soils characteristics.

\begin{tabular}{|c|c|c|c|c|}
\hline \multirow{2}{*}{ Soil } & $\begin{array}{c}\text { Organic } \\
\text { matter } \\
\mathrm{L}_{\mathrm{i}}(\%)\end{array}$ & $\begin{array}{c}\text { Natural water } \\
\text { content } \\
\mathrm{W}_{\mathrm{n}}(\%)\end{array}$ & $\begin{array}{c}\text { Natural degree } \\
\text { of saturation } \\
\mathrm{S}_{\mathrm{r}}(\%)\end{array}$ \\
\hline \multicolumn{2}{|c|}{$\begin{array}{c}\text { Kumamoto } \\
\text { VA }\end{array}$} & 48.95 & 181.3 & 93.1 \\
\hline \multirow{2}{*}{ Yabakei } & Y1 & 5.252 & 34.5 & 91.2 \\
\cline { 2 - 5 } & Y2 & 5.833 & 41.2 & 90.1 \\
\hline \multirow{2}{*}{ Asakura } & A1 & - & 18.6 & 18.6 \\
\cline { 2 - 5 } & A2 & - & 30.3 & 31.3 \\
\hline
\end{tabular}

\subsection{Methodology}

Disturbed and undisturbed natural specimens were collected. Undisturbed sampling was carried out using 5 $\mathrm{cm}$ in diameter and $5.1 \mathrm{~cm}$ in height steel moulds with a wall thickness of $1 \mathrm{~mm}$. A shaft and hammer were used to drive the mould with the sharp edge guided to cut through the ground as illustrated in Fig. 4 and Fig. 5 a.

Remoulded samples were compacted directly in an acrylic mould to the desired density and initial water content for standard soils and to the natural density and natural water content for natural soils. On the other hand, undisturbed samples contained in the steel moulds were installed into the acrylic mould and two O-rings [G-50 rubber rings] were used to prevent water and air from leaking through the space between the steel and the acrylic moulds surfaces as elucidated in Fig. 5 b. A layer of grease oil was applied to the internal surface of the acrylic mould and the external surface of the steel mould to reduce the friction and drive the steel mould smoothly into the acrylic mould, accordingly minimizing the degree of disturbance.

Prior to testing, samples, base and the microtensiometer were submerged into a water tank and a vacuum pressure of $80 \mathrm{kPa}$ was applied for 24 hours in order to get arid of any occluded air bubbles and assure full saturation of the whole specimen. Base was then removed from the tank and the micro-tensiometer and its pressure transducer were assembled to the base. Water was then flushed through the valves, water compartment beneath the ceramic disk and the drainage pipe in order to get arid of any occluded air bubbles within the system. The sample was then removed from the tank and a hole with diameter and depth equal to the micro-tensiometer dimensions was excavated using a drill bit. The sample was then installed, where the micro-tensiometer was guided carefully into the hole in order to avoid disturbing the sample and assure well contact between the ceramic cup and the surrounding soil particles.

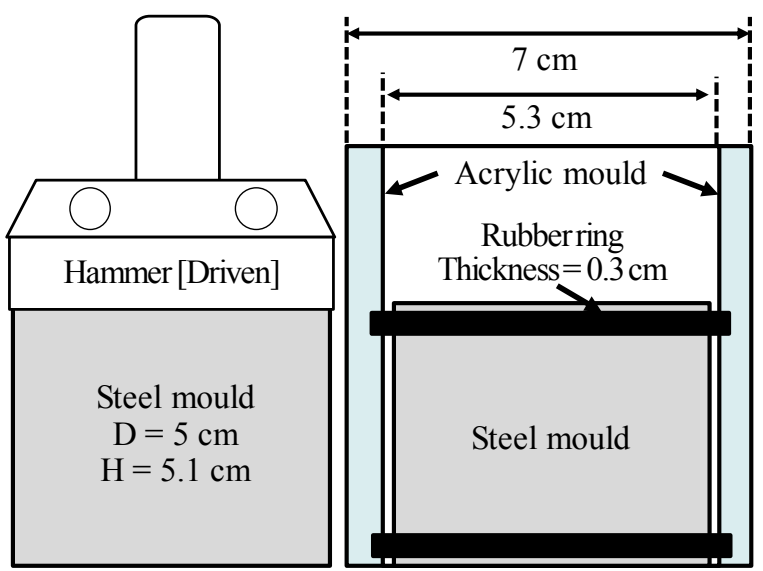

Fig. 4. Undisturbed sampling steel methodology (schematic).
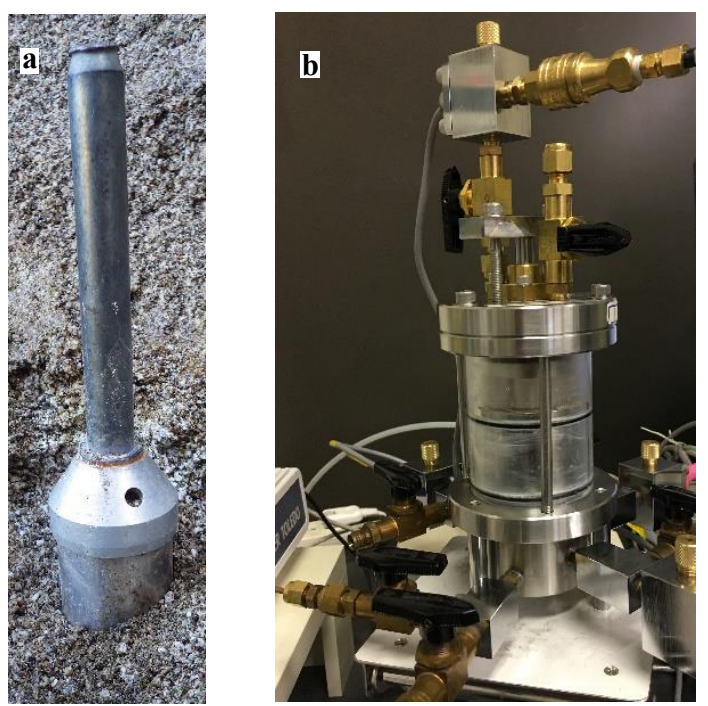

Fig. 5. Undisturbed samples. a) Undisturbed sampling. b) Undisturbed samples SWCC testing setup.

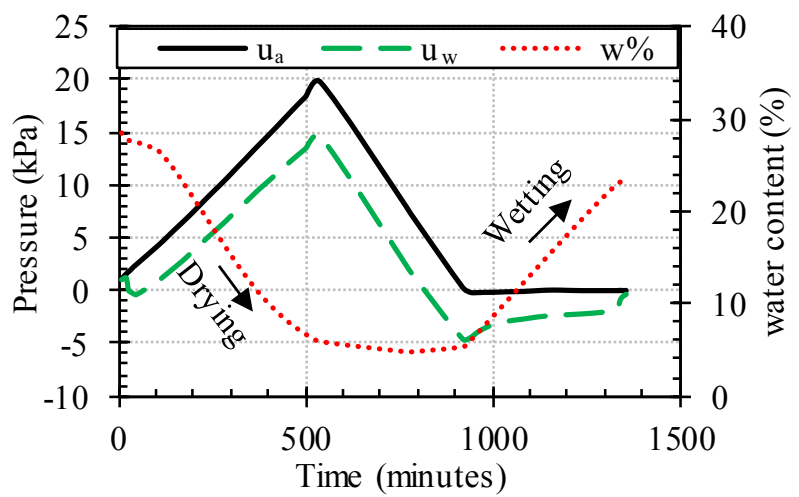

Fig. 6. Obtained raw data for Toyoura sand (acrylic mould). 
The cell was then assembled and the testing schedule was invoked into the software and the test was started. During testing, the air pressure $\left(\mathrm{u}_{\mathrm{a}}\right)$, pore water pressure $\left(\mathrm{u}_{\mathrm{w}}\right)$ and the water content deduced from the cumulative drained water are continuously recorded over a predetermined time interval as shown in Fig. 6. Fig. 7 illustrates the remoulded and undisturbed samples preparation process.

\section{Results and discussion}

\subsection{Validation of the system (standard soils)}

The proposed system was validated by obtaining the SWCC for two standard sands remoulded samples (K-7 and K-4 sands) and comparing the results to the SWCCs obtained using the conventional axis-translation technique (Tempe cell). Fig. 8 shows the SWCCs for K-7 and K-4 soils. The black square and red circled scattered plots represent the discrete data obtained using the conventional Tempe cell. While the solid and dashed lines represent the continuous data obtained using the developed CPM system under the drying phase. It can be observed that the SWCC obtained using the newly developed CPM system is in well agreement with the SWCC obtained using the conventional method with precise accurate capturing of the Air Entry Value (AEV) and the residual suction value.

\subsection{Undisturbed samples containing moulds}

As mentioned in section 2.3, a simple undisturbed sampling methodology including specially designed moulds was proposed. In order to evaluate the boundary conditions influence considering the undisturbed samples being contained in steel moulds, while the remoulded samples being contained in acrylic moulds, standard Toyoura sand remoulded samples were prepared by compacting the soil directly into the steel mould used for undisturbed sampling, then the steel mould was directly installed into the acrylic mould and the test was performed. Toyoura sand SWCCs obtained using samples contained in steel and acrylic moulds are illustrated in Fig. 9. It can be observed that the SWCC obtained using a sample contained in a steel mould is in well agreement with the SWCC obtained using a sample contained in an acrylic mould. Thus it can be concluded that the containing mould material has minor influence on the SWCC determination which can be neglected.

\subsection{Natural soils}

The SWCC is a function of the micro-pore network which can be significantly affected by the sample disturbance, handling, particles rearrangement and many other factors. In order to obtain a reliable representative results, samples disturbance should be minimized and natural conditions should be preserved during sampling, preparing and testing. The newly developed undisturbed samples SWCC obtaining system considers minimizing the disturbance and obtaining the SWCC in a very short time in order to avoid affecting the samples micro-structure and properties. In order to validate the system and as a trial to evaluate the degree of disturbance influence on the obtained results, undisturbed natural soil samples collected at three Geo-disaster affected sites in addition to remoulded samples compacted to the natural bulk densities and natural water contents were tested.

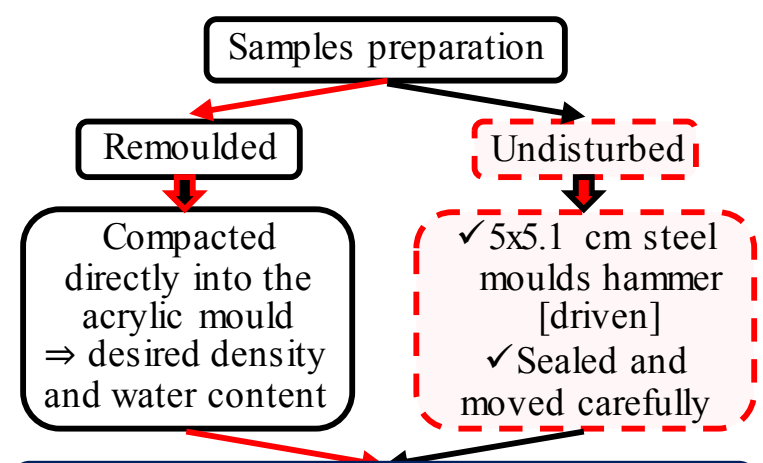

Submerged into a water tank $\Rightarrow$ a vacuum pressure $(80 \mathrm{kPa})$ was applied for 24 hours $\checkmark$

Sample was then removed from the tank

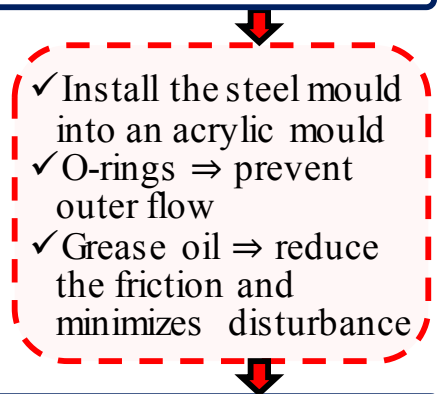

Excavate holes (micro-tensiometer) $\Rightarrow$ drill bit

Install the sample where the microtensiometer is guided into the hole

$\checkmark$ Minimize disturbance

$\checkmark$ Assure well contact (ceramic cup and the soil particles)

Fig. 7. Remoulded and undisturbed samples preparation.

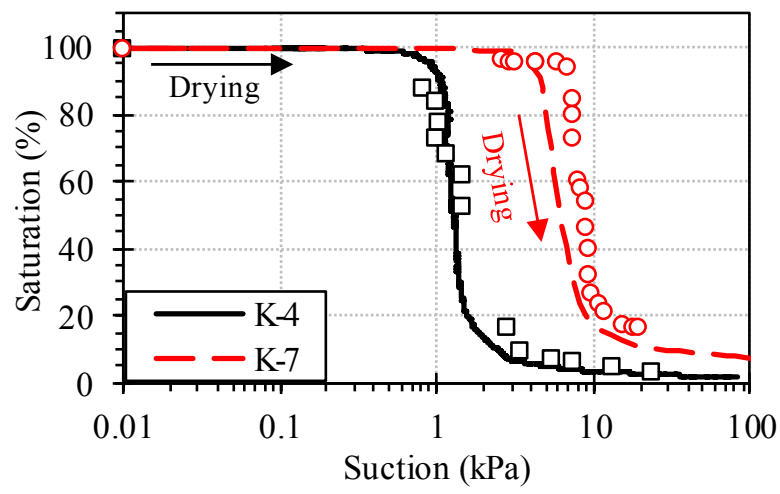

Fig. 8. K-7 and K-4 sands SWCCs. Lines represent the SWCCs obtained using the CPM system, while scatter plots represent the SWCCs obtained using the Tempe cells. 
Figs. 10, 11, and 12 illustrate the SWCCs of the natural soil samples collected at Kumamoto site, Asakura site and Yabakei site respectively. The solid black line and the dotted red line represent the SWCCs obtained for the undisturbed samples collected at locations 1 and 2 for Asakura and Yabakei sites, while they represent samples 1 and 2 collected at the same location for Kumamoto site. Both the drying and wetting phases SWCCs are elucidated for the undisturbed samples. The green line illustrated in Figs. 10 and 11 represents the SWCCs obtained using remoulded samples prepared with the same natural bulk density and natural water content for Kumamoto site and Asakura site (location 2) respectively. The black circled and red squared scatter plots indicate the natural water contents directly measured after sampling versus the corresponding natural suction value for Asakura and Yabakei sites. In general, it can be observed that using the newly developed undisturbed samples SWCC obtaining system and sampling methodology results in obtaining smooth continuous curves with the ability to capture the $\mathrm{AEV}$ and the residual suction value accurately under both the drying and wetting phases.

Comparing the undisturbed samples SWCCs to the remoulded samples SWCCs, it can be observed that the remoulded samples SWCCs are not in good agreement with the undisturbed samples SWCCs, where the AEV and saturated volumetric water content were shifted from $1.6 \mathrm{kPa}$ and 0.858 to $4 \mathrm{kPa}$ and 0.866 for Kumamoto soil, while they were shifted from $1.2 \mathrm{kPa}$ and 0.440 to $0.5 \mathrm{kPa}$ and 0.395 for Asakura soil. Thus, it should be noted that remoulded samples do not properly represent the in-situ conditions with significant error that should be carefully considered when conducting analysis and proposing countermeasures against such unsaturated soil related Geo-disasters. Finally, it can be concluded that the developed undisturbed soil water characteristics curve obtaining system is direct, rapid, reliable and simple. In addition, the proposed undisturbed sampling and testing methodology can be used to accurately evaluate the spatial variations of the SWCC regardless the heterogeneity of the soil profile.

\subsection{SWCC obtaining time}

A conventional SWCC test requires few weeks to few months depending on the soil type. The newly developed CPM system significantly reduces the testing time. Both standard Tempe cell and the newly developed CPM system require the same time for sample preparation and saturation process. Table 3 illustrates the time required for obtaining the SWCC using the developed CPM system under both drying and wetting phases. It takes less than one week to obtain both phases SWCCs for sandy soils using $0.05 \mathrm{kPa} / \mathrm{min}$. air pressurizing rate and a ceramic disk with an AEV of $100 \mathrm{kPa}$ and saturated hydraulic conductivity of $4.8 \times 10^{-9} \mathrm{~m} / \mathrm{s}$. Where in comparison to the conventional methods, the newly developed system is capable of accurately obtaining the SWCC in less than $20 \%$ of the time required using the conventional method. Considering the drying phase only, it can be observed that using the developed testing system, the drying phase

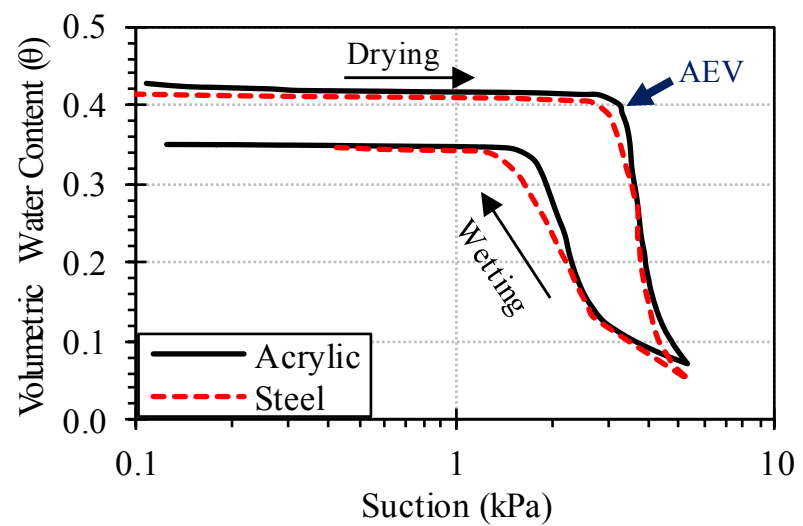

Fig. 9. Toyoura sand SWCCs obtained using samples contained in steel and acrylic moulds.

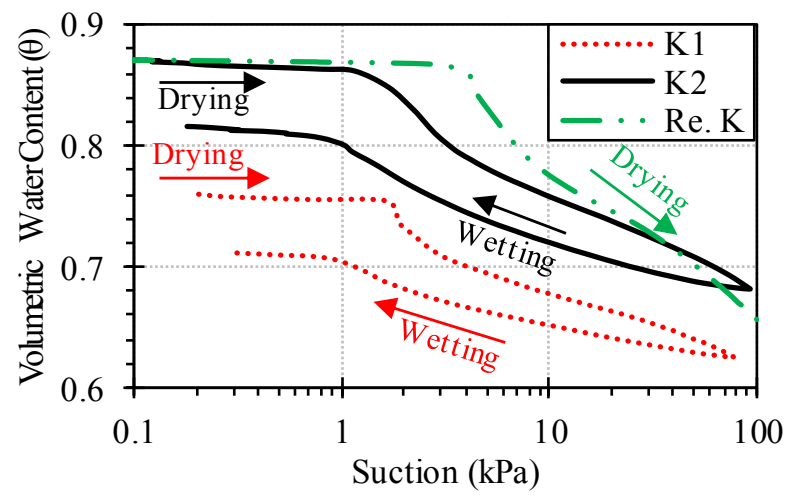

Fig. 10. Kumamoto undisturbed and remoulded samples SWCCs.

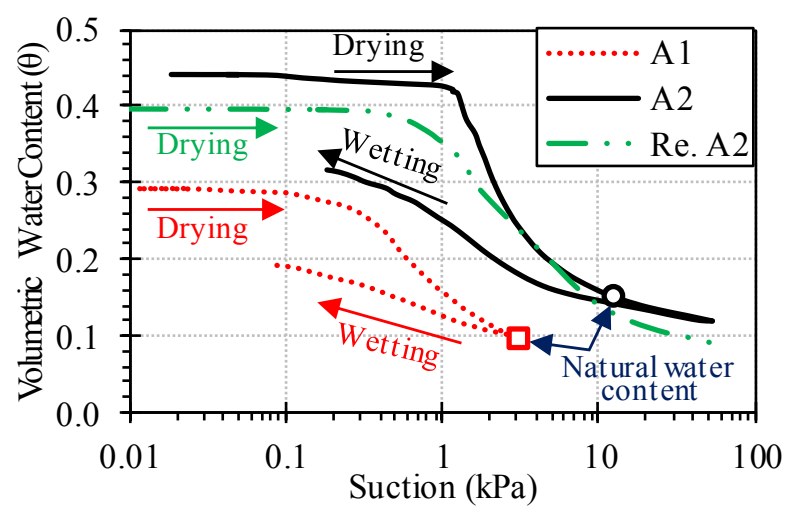

Fig. 11. Asakura undisturbed and remoulded samples SWCCs.

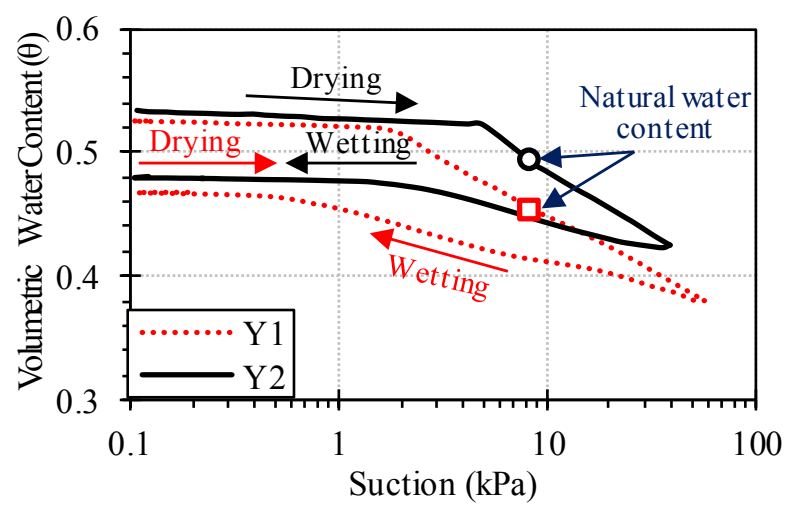

Fig. 12. Yabakei undisturbed samples SWCCs. 
SWCC can be obtained in less than one day, which counts for less than $10 \%$ of the time required using the conventional testing method [Tempe cell], where it took about 160 hours.

Finally, it can be concluded that the newly developed CPM device can be used for accurate, reliable determination of the SWCC in a very short time compared to the conventional methods.

Table 3. SWCC obtaining time (Toyoura sand).

\begin{tabular}{|l|c|}
\hline Step & Time $(\mathrm{h})$ \\
\hline 1. Specimen preparation & 1 \\
\hline 2. Saturation of the system & 24 \\
\hline 3. Cell preparation and setup & 1 \\
\hline 4. Drying phase & 13 \\
\hline 5. Wetting phase & 103 \\
\hline Total & 142 \\
\hline
\end{tabular}

\section{Conclusions}

Through this paper, a sampling methodology and a novel full automatic system adopting the Continuous Pressurization Method (CPM) which is capable of determining the Soil Water Characteristics Curve (SWCC) for both remoulded and undisturbed samples in a very short time was developed. It was found that remoulded samples do not properly represent the in-situ conditions with significant error that should be carefully considered when conducting analysis and proposing countermeasures against unsaturated soils related Geodisasters. In addition, the containing mould material has minor influence on the SWCC determination which can be neglected. Finally, it can be concluded that the developed undisturbed soil water characteristics curve obtaining system is direct, rapid, reliable and simple. In addition, the proposed undisturbed sampling and testing methodology can be used to accurately evaluate the spatial variations of the SWCC regardless the heterogeneity of the soil profile. Where using the developed system, the drying phase SWCC can be obtained in less than $10 \%$ of the time required using the conventional axis-translation technique (Tempe cell), while the SWCC for both drying and wetting phases can be obtained in less than $20 \%$ of the time required using the conventional axis-translation method.

The authors express their gratitude to Mr. Nakashima Michio (Kyushu university) for his great support.

\section{References}

1. D. G. Fredlund, A. Xing, M. D. Fredlund, S. L. Barbour. Canadian Geotechnical Journal. 33(3). 440448. (1996)

2. A. Klute. Water retention: laboratory methods. Methods of soil analysis: part 1-physical and mineralogical methods. 635-662. (1986)

3. D.C. Spanner. Journal of Experimental Botany. 145168. (1951)
4. G.W. Gee, M.D. Campbell, G.S. Campbell, J.H. Campbell. Soil Science Society of America Journal. 56(4). 1068-1070. (1992)

5. Japanese Geotechnical Society. Method and explanation of geotechnical test-the first revised edition-1. (2000)

6. N. Lu, A. Wayllace, J. Carrera, W.J. Likos. Geotechnical Testing Journal. 29(3). 230-241. (2006)

7. D. G. Fredlund, H. Rahardjo. Soil mechanics for unsaturated soils. John Wiley \& Sons. (1993)

8. N. Lu, W. J. Likos. Unsaturated soil mechanics. Wiley. (2004)

9. L.A Richards. Soil science. 51(5). 377-386. (1941)

10. A. Alowaisy, N. Yasufuku, R. Ishikura, R. Yamamoto, M. Hatakeyama. JSCE annual meeting. 55-56. (2017)

11. A. Alowaisy, N. Yasufuku, R. Ishikura, M. Hatakeyama, S. Kyono. JGS annual meeting. 713714. (2018)

12. M. Hatakeyama, S. Kyono, T. Kawahara. OYO technical report. 34. 23-54. (2015) [Japanese]

\section{Appendix I}

The following figures show the SWCC obtained for K-7 standard testing silica sand and Kumamoto volcanic ash utilizing the newly developed CPM system. Three air pressurizing rates were adopted $(0.05,0.5$ and 5 $\mathrm{kPa} / \mathrm{min}$.). It can be seen that the air pressurizing rate has minor influence on the SWCC determination utilizing the CPM that can be neglected [10]. Various natural and standard testing soils SWCCs determined using the CPM system can be found in literature $[10,11,12]$.
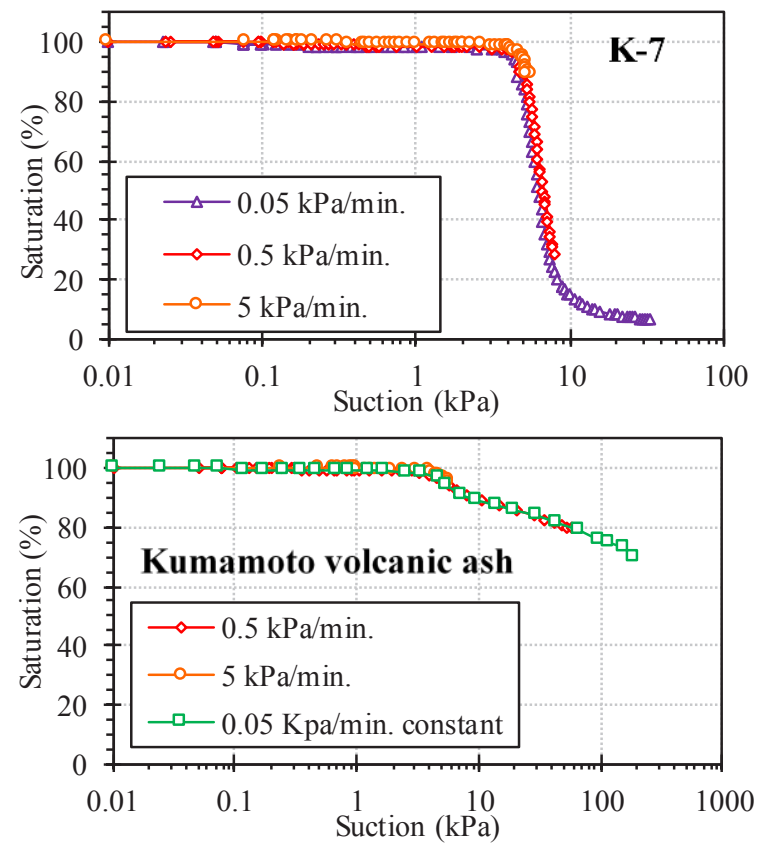

Fig.: K-7 standard testing silica sand and Kumamoto volcanic ash SWCCs determined utilizing the CPM system under $0.05,0.5$ and $5 \mathrm{kPa} / \mathrm{min}$. air pressurizing rate. 